\title{
Protective effect and related mechanisms of curcumin in rat experimental periodontitis
}

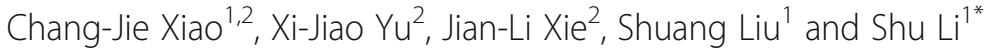

\begin{abstract}
Background: Curcumin exhibits anti-inflammatory effects and has been suggested as a treatment for inflammatory diseases. The aim of this study was to investigate the effects of curcumin on the lipopolysaccharide induced inflammatory response in rat gingival fibroblasts in vitro and ligation-induced experimental periodontitis in vivo, and to speculate the possible anti-inflammatory mechanism of curcumin.

Methods: The gingival fibroblasts were incubated with different concentrations of curcumin in the absence or presence of lipopolysaccharide (LPS). Concentrations of interleukin-1 $\beta(I L-1 \beta)$, tumor necrosis factor-a (TNF-a), osteoprotegerin (OPG) and soluble receptor activator of nuclear factor kappa-B ligand (RANKL) culture supernatants of rat gingival fibroblasts were determined by enzyme linked immunosorbent assay. The nuclear fraction of rat gingival fibroblasts was extracted and nuclear factor kappa-B (NF-kB) activation was assessed by western blotting to elucidate related mechanisms. Curcumin was given every two days by oral gavage. The gingival inflammation and alveolar bone loss between the first and second molars were observed by hematoxylin and eosin staining. Collagen fibers were observed by picro-sirius red staining. Alveolar bone loss was assessed by micro-CT analysis.
\end{abstract}

Results: Curcumin attenuated the production of IL-1 $\beta$ and TNF- $\alpha$ in rat gingival fibroblasts stimulated by LPS, and inhibited the LPS-induced decrease in OPG/SRANKL ratio and NF-KB activation. Curcumin significantly reduced gingival inflammation and modulated collagen fiber and alveolar bone loss in vivo.

Conclusions: curcumin modulates inflammatory activity in rat periodontitis by inhibiting NF-KB activation and decreasing the OPG/SRANKL ratio induced by LPS.

Keywords: Curcumin, NF-kB, OPG/RANKL, Periodontitis, Micro-CT

\section{Background}

Periodontitis is a prevalent oral inflammatory disease characterized by progressive gingival tissue inflammation, irreversible alveolar bone loss and deep periodontal pockets. It is caused by accumulation of profuse amounts of dental plaque. The conventional treatment for periodontitis is to reduce dental bacteria levels by scaling and root planing [1]. Antibiotics such as doxycycline have been used to alter the host response to the periodontal pathogens by disrupting the action of matrix metalloproteinase and to thus minimize host-mediated tissue

\footnotetext{
* Correspondence: lishu@sdu.edu.cn

${ }^{1}$ Shandong Provincial Key Laboratory of Oral tissue regeneration, Department of Periodontology, School and Hospital of Stomatology, Shandong

University, 44-1\# West Wenhua Road, Jinan, Shandong, China
}

Full list of author information is available at the end of the article destruction [2], but systemic use of antibiotics can interfere with normal body systems and may cause several side effects,such as drug resistance [3].

Treatment of periodontitis in traditional Chinese medicine or natural substances is one of the research points in recent years. Several compounds extracted from spices and herbs exhibit anti-inflammatory effects, which suggest potential pharmacological uses. Curcumin, the principal curcuminoid in turmeric (Curcuma longa), has been used as a food additive and herbal supplement because of its potential medicinal properties [4]. Curcumin has been shown to exhibit anti-inflammatory biological activity [5-8]. Gingival tissues are the first tissues affected during the initial stage of periodontitis [9]. Gingival fibroblasts, as the major cell type in gingival 
tissues, which stimulated by lipopolysaccharide (LPS) can activate the nuclear factor kappa-B (NF- $\mathrm{kB}$ ) signaling pathway and products inflammatory cytokines such as IL-1 $\beta$ and TNF- $\alpha$. Extensive research has demonstrated that the transcription factor NF- $\mathrm{KB}$ is a key component of the inflammatory process [10]. However, the anti-inflammatory effects of curcumin on LPS-stimulated rat gingival fibroblasts and the molecular mechanisms remain unclear. The expression and activation of OPG and RANKL are crucial for alveolar bone absorption and metabolism [11]. The present study was undertaken to investigated the hypothesis that curcumin would inhibit the LPS-induced inflammatory response in rats gingival fibroblasts in vitro and ligation-induced experimental periodontitis in vivo.

\section{Methods}

\section{Reagents}

LPS and curcumin were purchased from Sigma (USA). NF- $\mathrm{B}$ p-p65 and p-IкB $\alpha$ were purchased from Cell Signaling Technology (USA). IL- $1 \beta$, TNF- $\alpha$, OPG and soluble RANKL (sRANKL) ELISA kits were obtained from R \& D Systems (Minneapolis, MN, USA). Wistar rats for the ligation-induced experimental periodontitis model were obtained from the Laboratory Animal Center of Shandong University (Shandong, China). This study was approved by the Local Ethics Committee of the Animal Care and Use Committee of the School of Stomatology, Shandong University.

\section{Cell culture}

Normal gingival tissues were obtained from male Wistar rats (aged 5 weeks) that were clinically free of periodontal disease. Enzymatic digestion were adopted and maintained in Dulbecco's modified Eagle's medium (DMEM; Gibco, USA) containing $20 \%$ fetal bovine serum (FBS), $100 \mathrm{U} / \mathrm{mL}$ penicillin and $100 \mathrm{mg} / \mathrm{mL}$ streptomycin (Hyclone, Beijing, China). After reaching confluence, the cells were detached from the culture surface with $0.25 \%$ trypsin and subcultured in DMEM containing 10\% FBS and antibiotic solution. The medium was changed every $48 \mathrm{~h}$. Gingival fibroblasts between passages 4 and 7 were used in this study.

\section{Cell viability}

The cell viability of gingival fibroblasts was assessed using the MTT assay as previously described [12]. Briefly, gingival fibroblasts were seeded in 96-well plates $\left(1 \times 10^{4}\right.$ cells per well $)$ and cultured for $12 \mathrm{~h}$. The cells (LPS, LPS + $10 \mu \mathrm{M}$ curcumin, LPS $+20 \mu \mathrm{M}$ curcumin, $10 \mu \mathrm{M}$ curcumin, $20 \mu \mathrm{M}$ curcumin and normal fibroblasts as control $)(n=8)$ were incubated with different concentrations of curcumin in the absence or presence of LPS $(1 \mu \mathrm{g} / \mathrm{ml})[13,14]$ for $24 \mathrm{~h}$. Then, $20 \mu \mathrm{l}$ of MTT
(5 $\mathrm{mg} / \mathrm{ml}$ ) was added to each well and the cells were incubated for $4 \mathrm{~h}$. The medium was then removed and $150 \mu \mathrm{l}$ of DMSO was added to each well. Optical density was measured at $450 \mathrm{~nm}$ using a Bio-Rad microplate reader (model 680, Bio-Rad, USA).

\section{ELISA assay}

The concentrations of IL- $1 \beta$, TNF- $\alpha$, OPG and sRANKL in the culture supernatants of gingival fibroblasts incubated with different concentrations of curcumin in the absence or presence of LPS $(1 \mu \mathrm{g} / \mathrm{ml})$ for $24 \mathrm{~h}$ were measured using commercially available ELISA kits $[15,16]$. ELISA assays were performed according to the manufacturer's instructions.

\section{Protein extraction and western blotting}

The nuclear fraction of gingival fibroblasts was extracted for NF- $\mathrm{kB}$ evaluation using an Ambion PARIS system (Thermo Fisher). Protein concentrations were measured using a bicinchoninic acid quantitative protein analysis assay kit (Boshe, China). Proteins were separated on 10\% SDS gels and transferred onto polyvinylidene difluoride membranes (Millipore, USA). After being blocked in $0.1 \%$ Tween 20 in Tris-buffered saline containing 5\% nonfat dried milk for $1 \mathrm{~h}$ at room temperature, the membranes were incubated with NF-kB, p-p65 and $\mathrm{p}-\mathrm{I} \kappa \mathrm{B} \alpha$ (all diluted 1:1000) overnight at $4{ }^{\circ} \mathrm{C}$. The membranes were then rinsed with TBST for $10 \mathrm{~min}$ three times, and incubated with horseradish peroxidaselabeled second antibody (Beyotime). Immunoreactive bands were visualized on Canon film using enhanced chemiluminescence substrate solution (Millipore). Histone H3 (antibody diluted 1:10000) was used as an internal control.

\section{Animals}

Twenty-four male Wistar rats that had undergone this ligation procedure were randomly distributed into the following 3 groups: a ligation-only (L) group, a group treated with $30 \mu \mathrm{g} / \mathrm{g}$ body weight curcumin $\left(\mathrm{L}+\mathrm{C}_{30}\right)$, and a group treated with $100 \mu \mathrm{g} / \mathrm{g}$ body weight curcu$\min \left(\mathrm{L}+\mathrm{C}_{100}\right)$. Curcumin diluted in corn oil vehicle was administered every 2 days by oral gavage, starting the day before ligation. Animals in the L group were administered the same volume of the corn oil vehicle. Food and water were provided ad libitum.

\section{Ligation-induced experimental periodontitis}

The procedure used for ligation-induced experimental periodontitis was as previously described [17]. Briefly, a 4-0 silk suture and an orthodontic ligature wire were passed through the interdentium between the first and second molars using Dumont forceps, and then the silk suture was wound tightly around the orthodontic 
ligature wire to cover it. After the gingiva was lacerated by a dental probe, the orthodontic ligature wire was ligated firmly to the dental cervix of the right first lower molar.

\section{Micro-computerized tomography (micro-CT) analysis}

SkyScan 1176 (BRUKER, USA) at $65 \mathrm{kV}$ and $380 \mu \mathrm{A}$ was applied for micro-CT analysis. Mandibles were scanned at $9-\mu \mathrm{m}$ resolution. Three-dimensional (3D) volume viewing and analysis software (DataViewer, CT-volume and CT-analyser, SkyScan, Bruker, USA) were used to visualize and quantify $2 \mathrm{D}$ and $3 \mathrm{D}$ data on a personal computer output, and a standardized gray-scale value was used to visualize mineralized tissues only.

\section{Collagen fibers analysis}

Sections were deparaffinized, hydrated and washed, then stained with $0.1 \%$ picro-sirius red for $60 \mathrm{~min}$ and rinsed with hydrochloric acid $(0.01 \mathrm{M})$ for $2 \mathrm{~min}$. The sections were dehydrated and sealed with mounting medium, and then the gingival fibers were analyzed under a polarizing microscope (Olympus BHSP, Japan).

\section{Statistical analysis}

All data are presented as means \pm SD of three independent experiments. Data were statistically analyzed by one-way analysis followed by the Newman-Keuls post hoc test using SPSS 17.0 statistical software (SAS, Cary, NC, USA). $P<0.05$ was considered statistically significant.

\section{Results}

\section{Effects of curcumin on cell viability}

The cytotoxic effect of curcumin on rat gingival fibroblasts was assessed by the MTT assay. There was no significant difference in cell viability in LPS $+10 \mu \mathrm{M}$ curcumin-treated cells, LPS $+20 \mu \mathrm{M}$ curcumin-treated

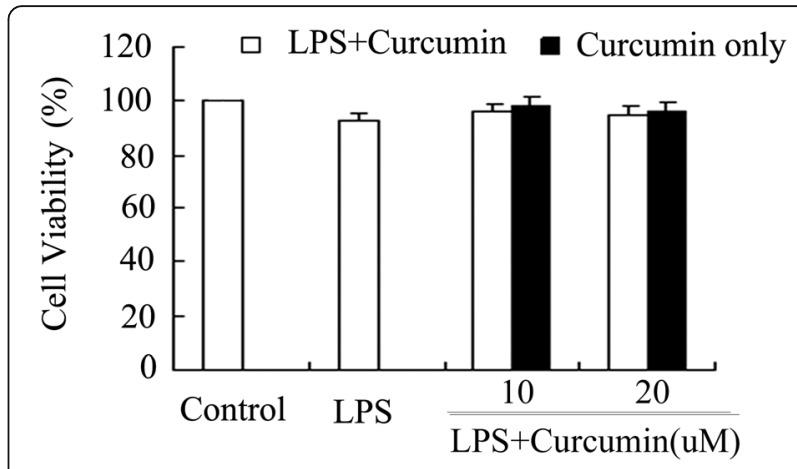

Fig. 1 Effects of curcumin on the cell viability of rat gingival fibroblasts. Cells were cultured with different concentrations of curcumin $(0,10$ and $20 \mu \mathrm{M})$ in the presence or absence of $1 \mu \mathrm{g} / \mathrm{ml}$ lipopolysaccharide (LPS). Cell viability was determined by MTT assay. Curcumin was not cytotoxic to gingival fibroblasts at 10 or $20 \mu \mathrm{M}(P>0.05)$

cells, $10 \mu \mathrm{M}$ curcumin-treated cells or $20 \mu \mathrm{M}$ curcumintreated cells compared with control fibroblasts $(P>$ $0.05)$. These results show that 10 and $20 \mu \mathrm{M}$ curcumin were not cytotoxic to gingival fibroblasts (Fig. 1). Thus, curcumin was used at 10 and $20 \mu \mathrm{M}$ in the subsequent in vitro studies.

\section{Effects of curcumin on TNF- $\alpha$ and IL- $1 \beta$ expression in gingival fibroblasts}

The culture supernatants of gingival fibroblasts treated with LPS, LPS $+10 \mu \mathrm{M}$ curcumin, and LPS $+20 \mu \mathrm{M}$ curcumin, and from the untreated control cells were tested. TNF- $\alpha$ and IL- $1 \beta$ in culture supernatants were markedly elevated in the LPS group comparing with the Control group $(P<0.05) .10$ and $20 \mu \mathrm{M}$ Curcumin decreased the levels of TNF- $\alpha$ and IL-1 $\beta$ stimulated by LPS in the culture supernatants of gingival fibroblasts $(P<0.05)$ (Fig. 2).

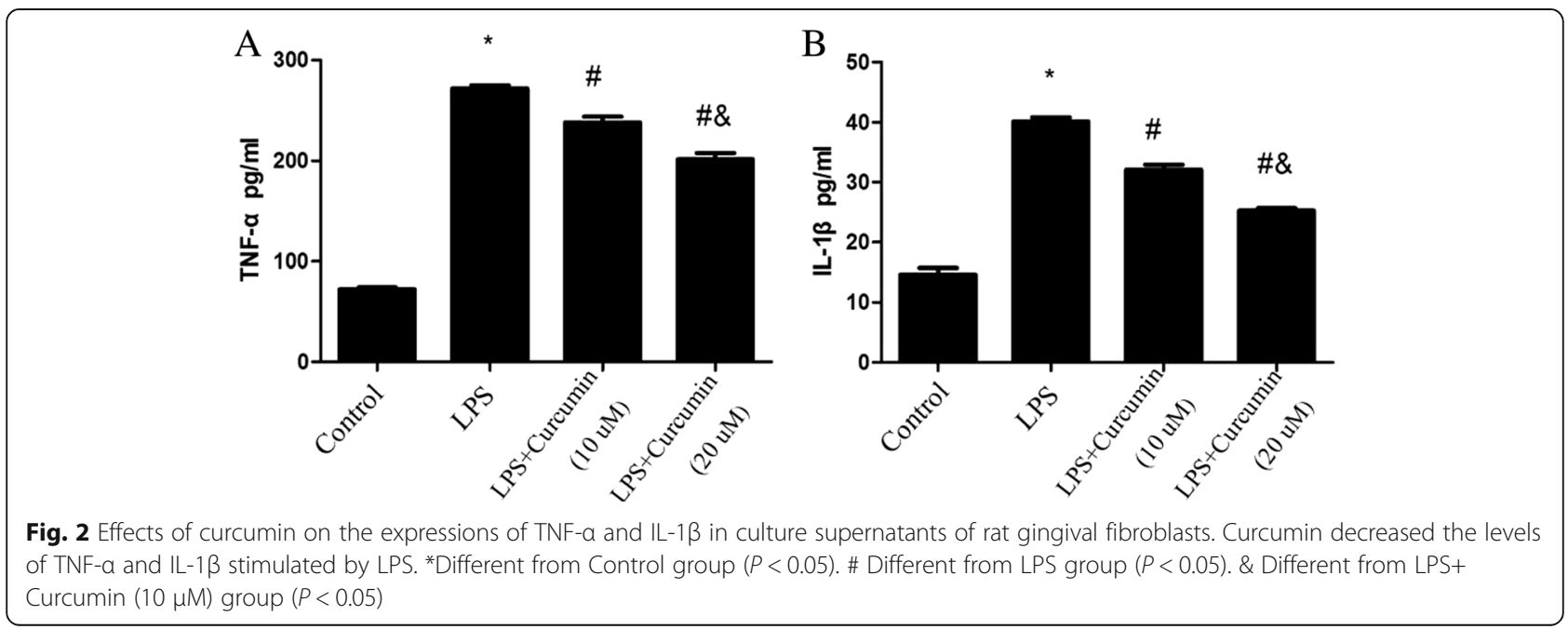




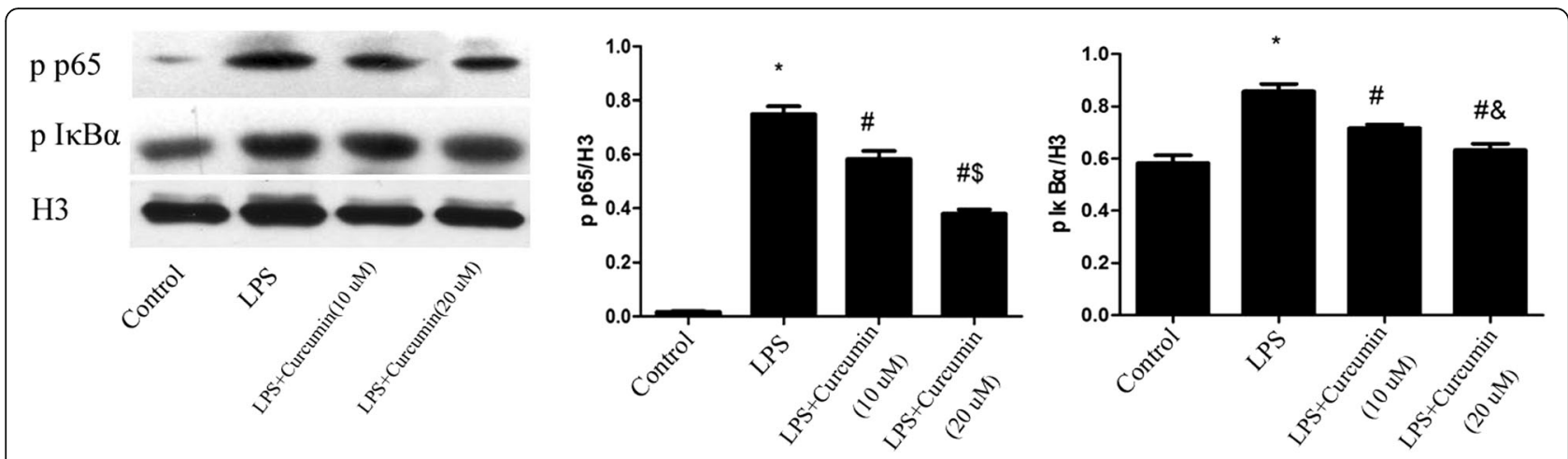

Fig. 3 Effects of curcumin on LPS-induced NF-KB activation. Curcumin significantly inhibited NF-KB activation induced by LPS. *Different from Control group $(P<0.05)$. \# Different from LPS group $(P<0.05)$. \& Different from LPS+ Curcumin $(10 \mu \mathrm{M})$ group $(P<0.05)$

\section{Effects of curcumin on LPS-induced NF-KB activation in} vitro

Cells were treated with curcumin $(10,20 \mu \mathrm{M})$ in the presence of LPS $(1 \mu \mathrm{g} / \mathrm{ml})$ for $24 \mathrm{~h}$. Cell nuclear protein samples were analyzed by western blotting. The results showed that LPS significantly increased NF- $\mathrm{B}$, p-p65 and $\mathrm{p}-\mathrm{I} \kappa \mathrm{B} \alpha$ levels $(P<0.05)$. Moreover, curcumin significantly inhibited LPS-induced NF- $\mathrm{B}$ activation $(P<$ 0.05).* Different from Control group $(P<0.05)$. \# Different from LPS group $(P<0.05)$. \& Different from LPS+ Curcumin $(10 \mu \mathrm{M})$ group $(P<0.05)$ (Fig. 3$)$.

\section{Effects of curcumin on OPG/sRANKL ratio in gingival fibroblasts}

The level of sRANKL in LPS-treated cells was significantly higher than that in control cells $(P<0.05)$. OPG release was significantly decreased when gingival fibroblasts were treated with LPS. Therefore, the OPG/ sRANKL ratio decreased significantly in the LPS-treated cells. Curcumin reduced sRANKL release from gingival fibroblasts, and also increased OPG release. Thus, curcumin inhibited the LPS-induced decrease in the OPG/sRANKL ratio $(P<0.05)$ (Fig. 4$)$.

\section{Effects of curcumin on ligation-induced experimental periodontitis in vivo}

Alveolar bone loss in the mandible between the first and second molars was observed by micro-CT (Fig. 5). Alveolar bone loss was observed in all three groups of rats. Alveolar bone crest height was obviously decreased, and notable alveolar bone loss between the first and second molars was observed in the L group (Fig. 6). Alveolar bone loss was reduced in the $\mathrm{L}+\mathrm{C}_{30}$ and $\mathrm{L}+\mathrm{C}_{100}$ groups.

The histological changes in rat experimental periodontitis with the treatment of curcumin. Histological analysis revealed gingival inflammation in all three groups. However, a significant reduction in gingival inflammation and bone loss was observed in the $\mathrm{L}+\mathrm{C}_{30}$ and $\mathrm{L}+$ $\mathrm{C}_{100}$ groups (Fig. 7). According to Picrosirius red staining, seriously collagen fiber destructions were observed in the $\mathrm{L}$ group. The fiber bundles were scattered and
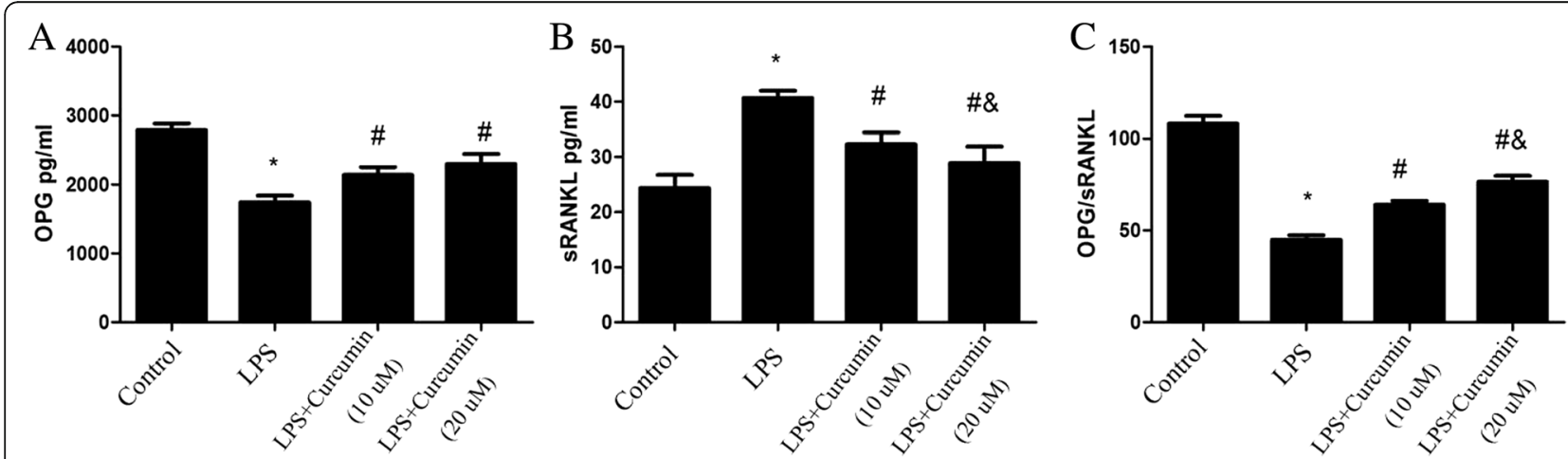

Fig. 4 Effects of curcumin on OPG/sRANKL ratio in culture supernatants of rat gingival fibroblasts. LPS downregulated OPG release from gingival fibroblasts; Curcumin reduced the downregulation (a). The sRANKL level in the culture supernatant of the LPS-treated cells was significantly higher than that of the control cells. LPS upregulated sRANKL release from gingival fibroblasts; curcumin reduced this upregulation (b). The OPG/ SRANKL ratio decreased significantly in the LPS group. Curcumin inhibited the LPS-induced decrease in the OPG/SRANKL ratio (c). *Different from Control group $(P<0.05)$. \# Different from LPS group $(P<0.05)$. \& Different from LPS+ Curcumin $(10 \mu M)$ group $(P<0.05)$ 


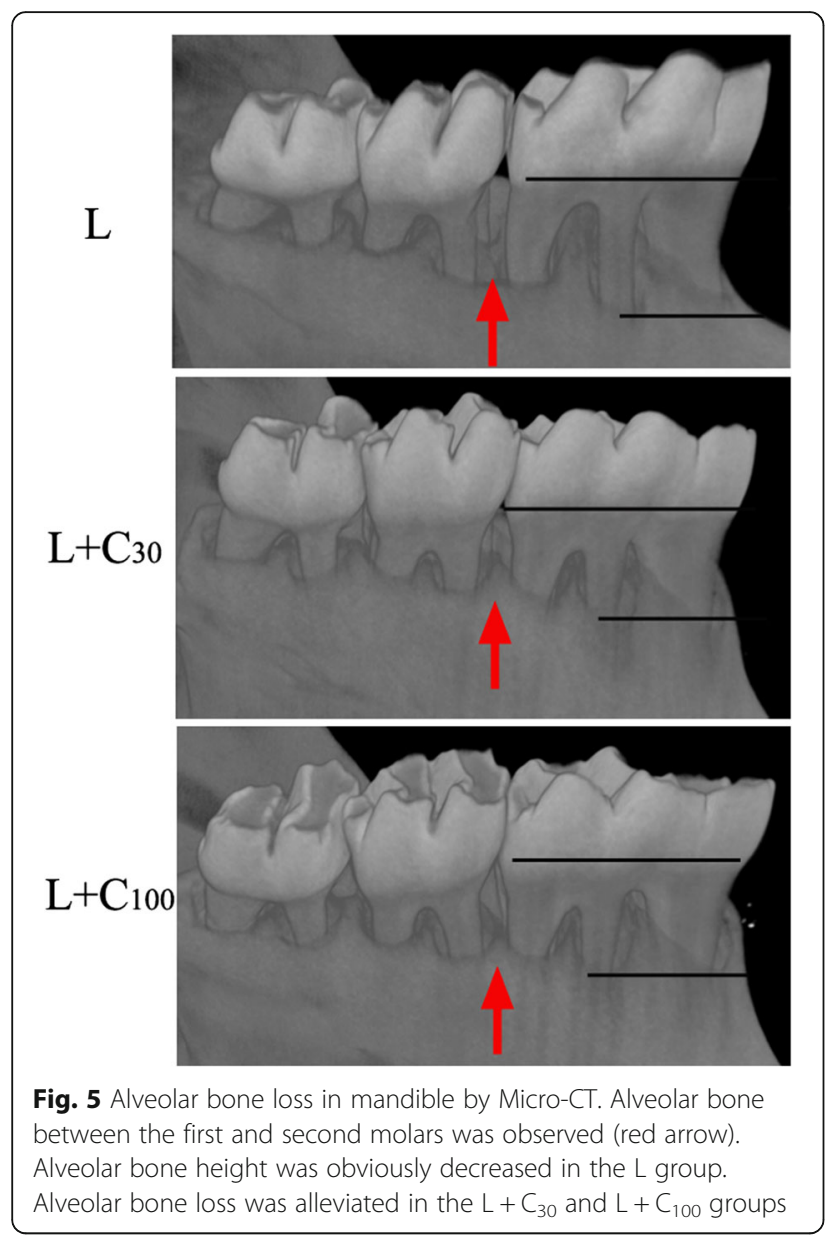

disordered. This collagen fiber destructions were also alleviated in the $\mathrm{L}+\mathrm{C}_{30}$ and $\mathrm{L}+\mathrm{C}_{100}$ groups (Fig. 8).

\section{Discussion}

Curcumin has been demonstrated to have various biological properties, including anti-inflammatory, antioxidant, antimicrobial, and antiviral effects. Because of these properties, curcumin provides a very promising approach for the treatment of periodontitis $[18,19]$. This study aimed to investigate the anti-inflammatory effects of curcumin on LPS-stimulated rat gingival fibroblasts and the underlying molecular mechanisms of these effects, which remain unclear. The cytotoxic effect of curcumin on rat gingival fibroblasts was assessed by the MTT assay in vitro. There was no significant difference between curcumin-treated fibroblasts and normal fibroblasts. So we did not use any negative or placebo controls in vivo for the consistency of experimental comparisons as we mainly aimed at the mechanism of curcumin in anti-inflammatory action.

TNF- $\alpha$ and IL-1 $\beta$, as two of the important pro-inflammatory mediators, were significantly up-regulated in the process of periodontitis [20,21], which are actively involved in jeopardizing periodontal tissues by affecting the activities of leukocytes, oteoclasts and collagenolytic enzyme MMPs to mediate alveolar bone resorption and collagen destruction $[22,23]$. So, in this study we chose TNF- $\alpha$ and IL- $1 \beta$ to examine the effect of curcumin on the production of these cytokines, since these cytokines participate to various extent in the production and the
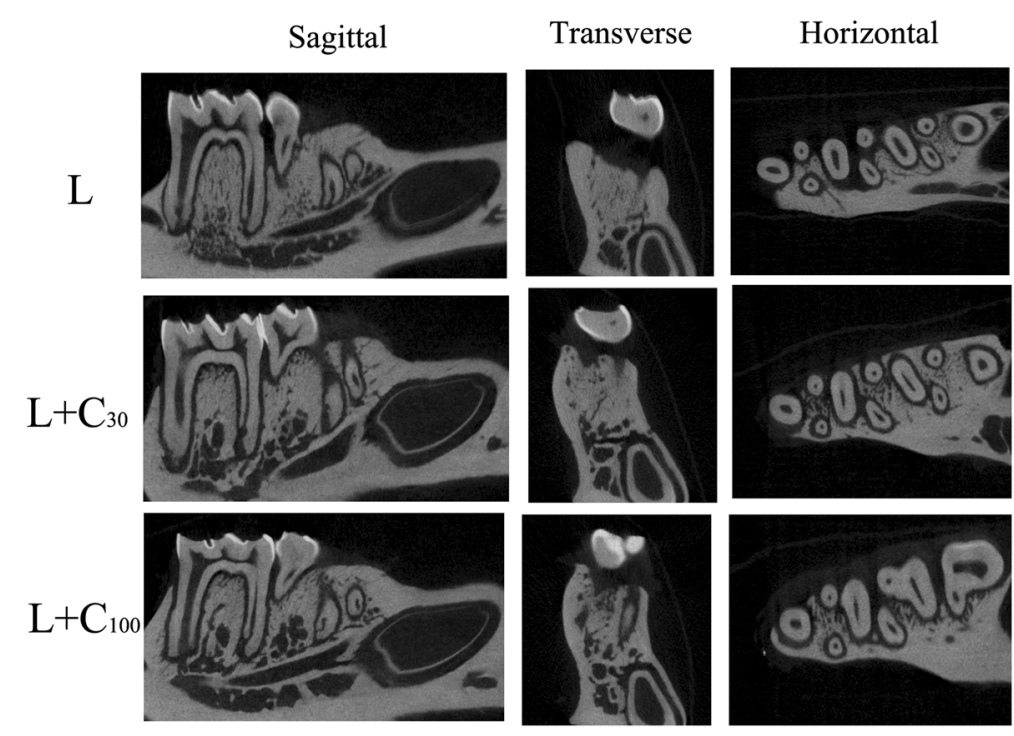

Fig. 6 Three-dimensional images of alveolar bone loss in rat experimental periodontitis by Micro-CT. Alveolar bone loss was observed in all the three groups. Obvious alveolar bone loss between the first and second molars was observed in the $L$ group. Alveolar bone loss was alleviated in the groups that underwent ligation in combination with treatment with $30 \mu \mathrm{g} / \mathrm{g}$ body weight curcumin $\left(\mathrm{L}+\mathrm{C}_{30}\right)$ or $100 \mu \mathrm{g} / \mathrm{g}$ body weight curcumin $\left(L+C_{100}\right)$ 


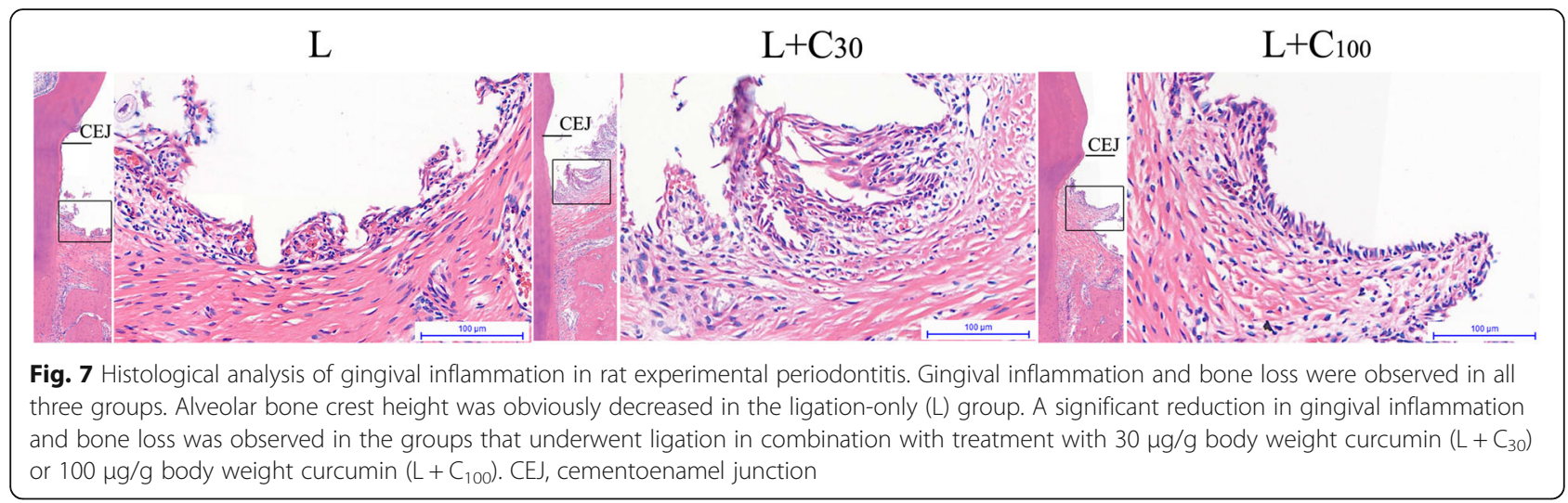

development of inflammation through recruitmnt and activation of inflammatory cells [24].

Gingival tissues were first invaded and stimulated by periodontal bacteria and their metabolic products in the initial process of periodontitis. The overproduction of IL-1 $\beta$ and TNF- $\alpha$ have been known to play important roles in periodontal inflammatory degradation [25]. According to our ELLSA results, curcumin inhibited the production of IL- $1 \beta$ and TNF- $\alpha$ in rat gingival fibroblasts induced by LPS, which showed that curcumin has potential role in modulating immune response associated with periodontal diseases.

To investigate the inflammatory mechanism, the effects of curcumin on LPS-induced NF-kB activation were detected by western blotting. Results showed that curcumin significantly inhibited upregulated NF-kB p65 and $\mathrm{I} \kappa \mathrm{B}$ phosphorylation induced by LPS.

NF- $\mathrm{KB}$ activation can stimulate a number of inflammatory events and amplify the inflammatory responses, including inducing adhesion molecules, and activating matrix metalloproteinase, which occur in periodontal disease process. NF- $\mathrm{kB}$ activation in gingival fibroblasts leads to the over-release of proinflammatory cytokines IL-1 $\beta$ and TNF- $\alpha$, which further enhanced periodontal tissue destruction. IL-1 and TNF- $\alpha$ also promote the recruitment and activity of osteoclasts, by enhancing production of a crucial osteoclastogenic factor, the Receptor Activator of Nuclear Factor к B Ligand (RANKL) and favor bone destruction [26].

The expression/activation of OPG and RANKL are crucial for alveolar bone absorption and metabolism $[27,28]$. The osteoclast differentiates from monocyte/ macrophage precursors under the regulation of RANKL/ RANK signaling. OPG is a secreted protein that protects bone from excessive resorption by binding to RANKL and preventing it from binding to RANK [29-31]. Soluble RANKL (sRANKL) and OPG from gingival fibroblasts stimulated by LPS may interrupt alveolar bone metabolism by paracrine secretion. Thus, OPG/sRANKL ratio is a major determinant. According to our results, OPG/ sRANKL ratio in culture supernatants of gingival fibroblasts was decreased when incubated with LPS, curcumin

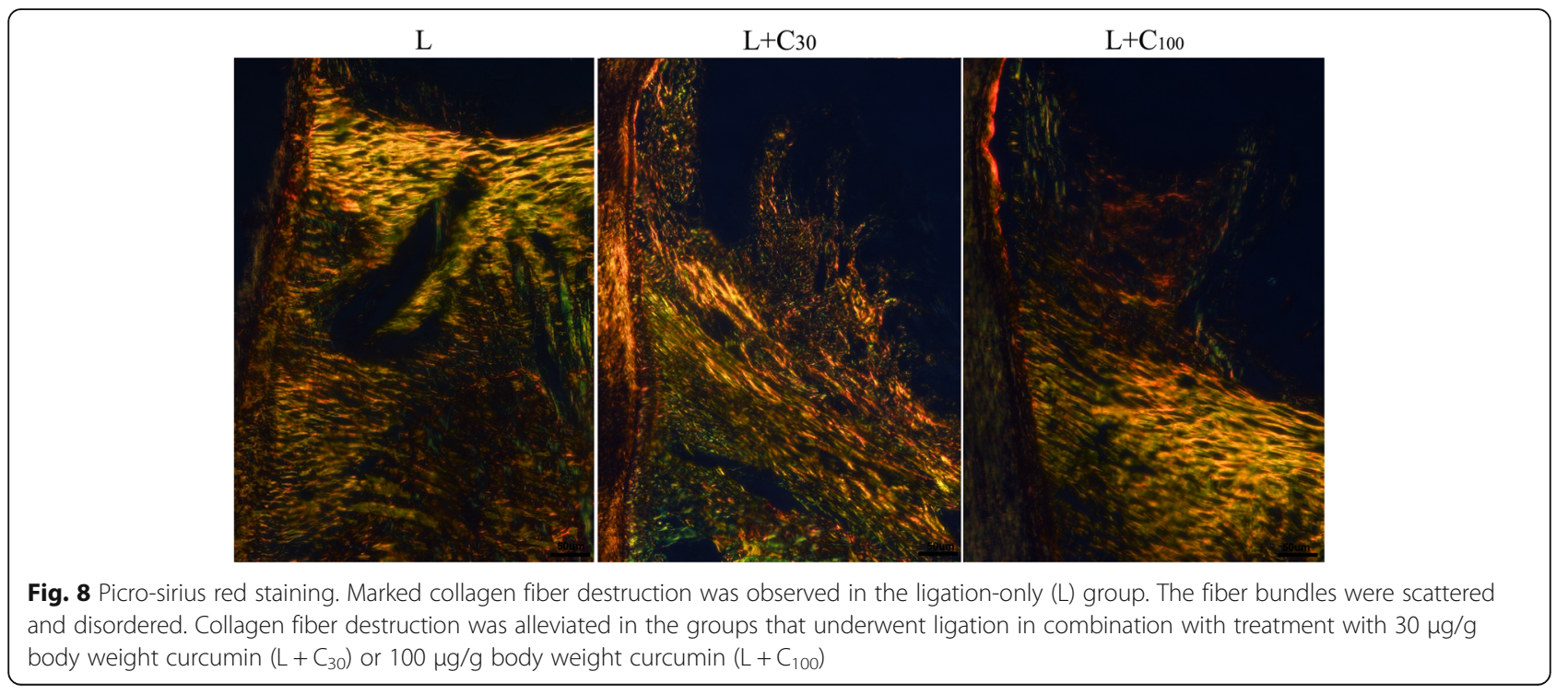


alleviated LPS-induced down-regulated OPG/sRANKL ratio. Curcumin may alleviate LPS-induced osteoclast activation and alveolar bone absorption by down-regulating OPG/sRANKL ratio.

In vivo, histological observation and micro-CT results showed gingival inflammation and alveolar bone loss was observed in rat experimental periodontitis. Both 30 and $100 \mu \mathrm{g} / \mathrm{g} /$ body weight of curcumin could alleviate the gingival inflammation and alveolar bone loss [32-35]. According to Picrosirius red staining, the fiber bundles became scattered and disordered in rat experimental periodontitis. Collagen fiber destructions were also alleviated by curcumin.

\section{Conclusion}

In the present study, we provided new evidence on the inhibitory effect of curcumin on inflammatory activity. Curcumin significantly reduced gingival inflammation and modulated collagen fiber and alveolar bone loss in vivo. Curcumin can significantly inhibit NF- $\mathrm{kB}$ activation and decrease the OPG/sRANKL ratio induced by LPS. This study provides a new anti-inflammatory therapeutic for periodontal diseases.

\section{Acknowledgements}

The authors would like to thank all participants who willingly participated in this study. We thank Ruth Tunn, PhD, from Liwen Bianji, Edanz Editing China for editing the English text of a draft of this manuscript.

\section{Funding}

This work was partly supported by National Natural Science Foundation of China (81271138) awarded to Shu Li. Natural Science Foundation of Shandong Province (ZR2017QH007) awarded to Xijiao Yu.

\section{Availability of data and materials}

The datasets supporting the conclusions of this article are available in the Shandong Provincial Key Laboratory, Department of Periodontology, School and Hospital of Stomatology, Shandong University, Shandong, China.

\section{Authors' contributions}

SL and XJY carried out the conception and design of the study. CJX participated in the sequence alignment and drafted the manuscript. $J \mathrm{LX}$ and $\mathrm{SL}$ performed cell culture and statistical analysis. All authors read and approved the final manuscript.

\section{Ethics approval and consent to participate}

This study was approved by the Local Ethics Committee of the Animal Care and Use Committee of the School of Stomatology, Shandong University and written consent forms were signed by all participants (No. GD201506).

\section{Consent for publication}

Not applicable.

\section{Competing interests}

The authors declare that they have no competing interests.

\section{Publisher's Note}

Springer Nature remains neutral with regard to jurisdictional claims in published maps and institutional affiliations.

\section{Author details}

${ }^{1}$ Shandong Provincial Key Laboratory of Oral tissue regeneration, Department of Periodontology, School and Hospital of Stomatology, Shandong University, 44-1\# West Wenhua Road, Jinan, Shandong, China. Department of Endodontics, Jinan Stomatological Hospital, 101\# Jingliu Road, Jinan, Shandong, China.

Received: 17 January 2018 Accepted: 3 August 2018

Published online: 16 August 2018

\section{References}

1. Ebersole JL, Kirakodu S, Novak MJ, Stromberg AJ, Shen S, Orraca L, Gonzalez-Martinez J, Burgos A, Gonzalez OA. Cytokine gene expression profiles during initiation, progression and resolution of periodontitis. J Clin Periodontol. 2014:41:853-61.

2. Goodson JM. Antimicrobial strategies for treatment of periodontal diseases. Periodontol 2000. 1994:5:142-68.

3. Garala K, Joshi P, Shah M, Ramkishan A, Patel J. Formulation and evaluation of periodontal in situ gel. Int J Pharm Investig. 2013;3:29-41.

4. Schaffer M, Schaffer PM, Bar-Sela G. An update on Curcuma as a functional food in the control of cancer and inflammation. Curr Opin Clin Nutr Metab Care. 2015;18:605-11.

5. Guimarães MR, de Aquino SG, Coimbra LS, Spolidorio LC, Kirkwood KL, Rossa C Jr. Curcumin modulates the immune response associated with LPSinduced periodontal disease in rats. Innate Immun. 2012;18:155-63.

6. Jurenka JS. Anti-inflammatory properties of curcumin, a major constituent of Curcuma longa: a review of preclinical and clinical research. Altern Med Rev. 2009;14:141-53.

7. Shehzad A, Ha T, Subhan F, Lee YS. New mechanisms and the antiinflammatory role of curcumin in obesity and obesity-related metabolic diseases. Eur J Nutr. 2011;50:151-61.

8. Wang W, Sukamtoh E, Xiao H, Zhang G. Curcumin inhibits lymphangiogenesis in vitro and in vivo. Mol Nutr Food Res. 2015;59:2345-54

9. Cobb CM. Non-surgical pocket therapy: mechanical. Ann Periodontol. 1996; 1:443-90.

10. Abe $Y$, Hashimoto S, Horie T. Curcumin inhibition of inflammatory cytokine production by human peripheral blood monocytes and alveolar macrophages. Pharmacol Res. 1999;39:41-7.

11. Yu XJ, Xiao CJ, Du YM, Liu S, Du Y, Li S. Effect of hypoxia on the expression of RANKL/OPG in human periodontal ligament cells in vitro. Int J Clin Exp Pathol. 2015:8:12929-35.

12. Wang $Q B$, Sun LY, Gong ZD, Du Y. Veratric acid inhibits LPS-induced IL-6 and IL-8 production in human gingival fibroblasts. Inflammation. 2015;39: 237-42.

13. Oliveira JR, Jesus D, Figueira LW, Oliveira FE, Pacheco Soares C, Camargo SE, Jorge AO, Oliveira LD. Biological activities of Rosmarinus officinalis $L$. (rosemary) extract as analyzed in microorganisms and cells. Exp Biol Med (Maywood). 2017;242(6):625-34

14. Aroonrerk N, Niyomtham N, Yingyoungnarongkul BE. Anti-inflammation of $\mathrm{N}$-Benzyl-4-Bromobenzamide in lipopolysaccharide-induced human gingival fibroblasts. Med Princ Pract. 2016;25(2):130-6.

15. Wan J, Jiang F, Qingsong X, Chen D, He J. Alginic acidoligosaccharide accelerates weaned pig growth through regulating antioxidant capacity, immunity and intestinal development. RSC Adv. 2016:6(90):87026-35.

16. Wan J, Chen D, Yu B, Luo Y, Mao X. Leucine protects against skeletal muscle atrophy in lipopolysaccharide-challenged rats. J Med Food. 2017;20(1):93-101.

17. Yu X, Gong Z, Lin Q, Wang W, Liu S, Li S. Denervation effectively aggravates rat experimental periodontitis. J Periodontal Res. 2017; 52(6):1011-20.

18. Akram M, Uddin S, Ahmed A, Usmanghani K, Hannan A, Mohiuddin E, et al. Curcuma longa and curcumin: A review article. Rom J Biol Plant Biol. 2010; 55:65-70.

19. Motterlini R, Foresti R, Bassi R, Green CJ. Curcumin, an antioxidant and antiinflammatory agent, induces heme oxygenase- 1 and protects endothelial cells against oxidative stress. Free Radic Biol Med. 2000;28:1303-12.

20. Jiang ZL, Cui YQ, Gao R, Li Y, Fu ZC, Zhang B, Guan CC. Study of TNF-a, IL$1 \beta$ and LPS levels in the gingival crevicular fluid of a rat model of diabetes mellitus and periodontitis. Dis Markers. 2013:34:295-304.

21. Noguchi T, Ebina K, Hirao M, Kawase R, Ohama T, Yamashita S, Morimoto T, Koizumi K, Kitaguchi K, Matsuoka H, Kaneshiro S, Yoshikawa H. Progranulin plays crucial roles in preserving bone mass by inhibiting TNF-a-induced osteoclastogenesis and promoting osteoblastic differentiation in mice. Biochem Biophys Res Commun. 2015;465:638-43.

22. Graves DT, Cochran D. The contribution of interleukin-1 and tumor necrosis factor to periodontal tissue destruction. J Periodontol. 2003;74:391-401. 
23. Geivelis M, Turner DW, Pederson ED, Lamberts BL. Measurements of interleukin-6 in gingival crevicular fluid fromadults with destructive periodontal disease. J Periodontol. 1993;64:980-3.

24. Lapérine $\mathrm{O}$, Cloitre $\mathrm{A}$, Caillon J, Huck $\mathrm{O}$, Buqueno IM, Pilet $\mathrm{P}$, Sourice $\mathrm{S}$, Le Tilly E, Palmer G, Davideau JL, Geoffroy V, Guicheux J, Beck-Cormier S, Lesclous P. Interleukin-33 and RANK-L interplay in the alveolar bone loss associated to periodontitis. PLoS One. 2016;11:0168080.

25. Page RC. The role of inflammatory mediators in the pathogenesis of periodontal disease. J Periodontal Res. 1999;26:230-42.

26. Hienz SA, Paliwal S, Ivanovski S. Mechanisms of bone resorption in periodontitis. J Immunol Res. 2015;2015:615486.

27. Yuan H, Gupte R, Zelkha S, Amar S. Receptor activator of nuclear factor kappa B ligand antagonists inhibit tissue inflammation and bone loss in experimental periodontitis. J Clin Periodontol. 2011;38:1029-36.

28. Yu X, Lv L, Zhang J, Zhang T, Xiao C, Li S. Expression of neuropeptides and bone remodeling-related factors during periodontal tissue regeneration in denervated rats. J Mol Hist. 2015;46:195-203.

29. Boyce BF, Xing L. Functions of RANKL/RANK/OPG in bone modeling and remodeling. Arch Biochem Biophys. 2008;15:139-46.

30. LV L, Wang Y, Zhang J, Zhang T, Li S. Healing of periodontal defects and calcitonin gene related peptide expression following inferior alveolar nerve transection in rats. J Mol Histol. 2014:45:311-20.

31. Tong W, Wang Q, Sun D, Suo J. Curcumin suppresses colon cancer cell invasion via AMPK-induced inhibition of NF-KB, UPA activator and MMP9. Oncol Lett. 2016;12:4139-46.

32. Zhang Y, Gu Y, Lee HM, Hambardjieva E, Vranková K, Golub LM, Johnson F. Design,synthesisand biological activity of new polyenolic inhibitors of matrixmetalloproteinases: a focus on chemically-modified curcumins. Curr Med Chem. 2012;19(25):4348-458

33. Elburki MS, Moore DD, Terezakis NG, Zhang Y, Lee HM, Johnson F, Golub LM. A novel chemically modified curcumin reduces inflammation-mediated connective tissue breakdown in a rat model of diabetes: periodontal and systemic effects. J Periodontal Res. 2017;52(2):186-200.

34. Guimarães MR, Coimbra LS, de Aquino SG, Spolidorio LC, Kirkwood KL, Rossa C Jr. Potent anti-inflammatory effects of systemically administered curcumin modulate periodontal disease in vivo. J Periodontal Res. 2011; 46(2):269-79.

35. Elburki MS, Rossa C, Guimaraes MR, Goodenough M, Lee HM, Curylofo FA, Zhang Y, Johnson F, Golub LM. A novel chemically modified curcumin reduces severity of experimental periodontal disease in rats: initial observations. Mediators Inflamm. 2014:959471.

Ready to submit your research? Choose BMC and benefit from:

- fast, convenient online submission

- thorough peer review by experienced researchers in your field

- rapid publication on acceptance

- support for research data, including large and complex data types

- gold Open Access which fosters wider collaboration and increased citations

- maximum visibility for your research: over $100 \mathrm{M}$ website views per year

At BMC, research is always in progress.

Learn more biomedcentral.com/submissions 